\title{
INTERCULTURALIDADE, LETRAMENTO E ALTERNÂNCIA COMO FUNDAMENTOS PARA A EDUCAÇÃO INDÍGENA
}

\section{INTERCULTURALITY, LETTERING AND ALTERNATION AS FOUNDATIONS FOR INDIGENOUS PEOPLE EDUCATION}

Flávia Marinho Lisbôa*

\section{RESUMO}

O presente artigo reflete acerca do ensino bilíngue para alunos indígenas em contexto multicultural, apresentando uma proposta como resultado de um levantamento bibliográfico em busca de fundamentos que possam subsidiar a elaboração de modelos de ensino bilíngue para indígenas nas regiões sul e sudeste do Pará. Com isso, chegamos à proposição de que a tríade composta pela Interculturalidade, Letramento e Alternância pode fundamentar a construção de modelos de ensino na conjuntura recortada. Partimos das perspectivas teóricas da Linguística Aplicada (LA), área que estabelece um corte epistemológico com a Linguística no sentido de encaminhar suas teorias, metodologias e análises por proposições próprias. Esse corte é o que tem subsidiado estudos como os que consideram o ensino bilíngue, em prol de comunidades subalternizadas. Cientes de que para cada comunidade é preciso pensar um modelo de ensino bilíngue específico, considerando as especificidades do povo em questão (seus etnoconhecimentos, seus tempos, seus projetos de sociedade, sua cultura etc.), tomamos o cuidado aqui de esclarecer que não temos a pretensão de apresentar uma fórmula, mas elementos que possam inspirar construções em torno do ensino bilíngue em contextos com alunos indígenas. Chegamos a esses três elementos (Interculturalidade, Letramento e Alternância) norteados pela premissa de que o ensino bilíngue deve servir para que os sujeitos do campo possam circular nos espaços legitimados e transformar as estruturas de dominação e poder. Esse ensino deve servir para que os sujeitos originários não dependam do Outro para escrever sua história e para que possam lutar por equidade epistêmica. Assim, este trabalho reforça o entendimento maior de que trabalhar com língua exige um exercício interdisciplinar, possibilitando assim uma reflexão mais ampla sobre um objeto tão complexo, constituinte e constitutivo dos sujeitos.

Palavras-chave: bilinguismo; indígenas; linguística aplicada.

\section{ABSTRACT}

This article reflects on the bilingual education for indigenous students in a multicultural context, presenting a proposal as a result of a bibliographical survey in search of foundations that could subsidize the elaboration of models of bilingual education for indigenous people in the southern and southeastern regions of Brazilian state of Pará. In this direction, we come to the proposition that the triad composed by Interculturality, Literature and Alternation can

\footnotetext{
* Universidade Federal Rural da Amazônia. Belém PA. Brasil. flaviamlisboa@gmail.com http://dx.doi.org/10.1590/010318138649254275971
} 
base the construction of teaching models in the conjuncture researched. We start from the theoretical perspectives of Applied Linguistics (A.L.), an area of studies that establishes an epistemological cut with theoretical linguistics in order to direct its theories, methodologies and analyzes by its own propositions. This cut is what has subsidized studies such as those that consider bilingual education in favor of subalternized communities. Aware that for each community it is necessary to think of a specific bilingual teaching model, considering the specificities of the people in question (their ethno-knowledge, their times, their projects of society, their culture, etc.), we feel the need to clarify we do not intend to present a formula, but elements that can inspire constructions around bilingual education in the contexts of indigenous students. We come to these three guiding elements (interculturality, lettering and alternation) by the premise that bilingual education should serve to enable the subjects of the field to circulate in the legitimized spaces and transform the structures of domination and power. This bilingual teaching should serve so that the original subjects do not depend on the Other to write their history and so they can fight for epistemic equity. In this way, this work reinforces the greater understanding that working with language requires an interdisciplinary exercise, thus enabling a broader reflection on such a complex element, constituent and constitutive of subjects.

Keywords: bilingualism; indigenous people; applied linguistics.

\section{INTRODUÇÃO}

A mesorregião sudeste do Pará é um território que se constitui historicamente pelo conflito como reflexo da expansão do capital na Amazônia, responsável pelo início de uma acelerada migração de pessoas de todo o Brasil em função de recorrentes projetos de grandes proporções que se instalam ao longo da história na região. Nesse cenário, o convite de "integrar para não entregar" desconsiderou a existência de homens e mulheres nativos no território amazônico, autorizando que empresários e famílias de prestígio do sul e sudeste do país tomassem para si as terras da região, sem reconhecê-las como propriedades indígenas, entre outros povos. Estes tiveram seus territórios, assim como suas existências, ainda mais ameaçados por essa implantação do grande capital, impulsionado pelo governo militar a partir do Plano de Integração Nacional (PIN) na Amazônia, configurando a referida região como espaço de fronteira, com intensos confrontos entre os que chegavam e as populações tradicionais.

$\mathrm{O}$ que queremos destacar nesse contexto desenhado aqui é o fato de que a intensificação das disputas por território colocam os indígenas em constante posição de defesa e de luta por direitos e é certo que esse contato com o "homem branco" faz que os indígenas vivam hoje sob outras dinâmicas, fazendo parte de suas práticas discursivas a necessidade de negociar interesses e contrapartidas com grandes empresas responsáveis por megaprojetos na região e mesmo a necessidade de desenvolver atividades mais simples na busca de serviços (saúde, comércio, 
educação) na cidade, serviços esses demandados pelo contato com o homem branco e que não são oferecidos a contento nas aldeias.

Entre as demandas ocasionadas por essa mudança socioeconômica, enfocamos a educação, especificamente o ensino de língua para os indígenas nessa região ${ }^{1}$ que se configura como plurilíngue, considerando as várias línguas faladas pelos indígenas, o português vernáculo de cada povo e o português padrão ensinado nas escolas e cobrado pela sociedade. As regiões sul e sudeste do Pará abrigam os povos Gavião, Suruí Aikewara, Xikrin do Kateté, Guajajara, Atikun, Guarani, Parakanã, segundo dados da Funai. Assim, fazer proposições para o ensino de línguas nesse contexto plurilíngue é um desafio que exige mobilizar inúmeras categorias e, por isso mesmo, contextualizar e delimitar os sujeitos a serem tratados para que tal tarefa seja praticável, levando em consideração o universo de povos - para cada contexto seriam necessárias diferentes reflexões - e que cada grupo tem sua história diante das novas dinâmicas trazidas pela implantação do capital na Amazônia, evidenciando assim que não se pode fazer considerações sobre a língua sem pensar os seus falantes e suas condições de existência, como defende Calvet (2002, p. 12): "Ora, as línguas não existem sem as pessoas que as falam, e a história de uma língua é a história de seus falantes".

Por outro lado, nosso objetivo neste trabalho é o de apontar três fundamentos que nos chamaram a atenção nas propostas de modelos de ensino indicados por pesquisadores $^{2}$ que são referências na área de ensino de língua para indígenas, especialmente para pensar o bilinguismo aditivo, tipo de ensino bilíngue indicado quando se pensa em valorizar e ampliar o prestígio da língua e da cultura indígena diante do português. Nas leituras dos trabalhos desses pesquisadores, inspiramo-nos para propor fundamentos (que recorrentemente surgem nesses trabalhos, mas não de forma conjunta como fazemos aqui) para possíveis modelos de ensino bilíngue. Esses fundamentos são: Letramento, Alternância e Interculturalidade.

Não propomos aqui um modelo, pois, como já ressalvamos, a diversidade de povos na região sul $\backslash$ sudeste do Pará não nos permite apontar um modelo que contemple as peculiaridades e os projetos de sociedade de cada um deles. Desta feita, acreditamos que esses fundamentos somados, da forma como os apresentamos aqui, podem ser considerados pilares na construção de modelos específicos de ensino

1. Dados de 19 de maio de 2015 da Coordenação Regional do Baixo Tocantins/Marabá-PA da FUNAI apontam nas regiões sul e sudeste do Pará nove povos indígenas, que estão organizados em 39 aldeias, cujas línguas originárias são de troncos Tupi-Guarani e Jê, totalizando 5.161 dos 6.912 indígenas do Baixo Tocantins.

2. Entre eles destacamos Terezinha Maher, Marilda Cavalcanti, Gilvan Oliveira, Rainer Enrique Hamel, Catharine Walsh, entre outros. 
bilíngue. $\mathrm{O}$ que não quer dizer que eles são suficientes em si, não necessitando de outras categorias que colaborem na sustentação dos projetos educacionais de sociedades específicas.

\section{BILINGUISMO ADITIVO: UM FIM A SE BUSCAR}

Entre os diversos tipos de bilinguismo, destacamos dois para esta discussão: o subtrativo, no qual em uma relação diglóssica a língua de maior prestígio social sufoca e míngua os usos sociais da língua menos prestigiada; e o aditivo, em que as duas línguas são valorizadas, mas a segunda é tida como complementar à primeira, a língua materna. Essas definições servem para situar nossa discussão no que defendemos neste trabalho como o princípio norteador para o ensino de língua para indígenas: o bilinguismo aditivo ${ }^{3}$. Oliveira (1999) orienta que essa deve ser a premissa para que os indígenas tenham suas línguas maternas valorizadas, legitimando e ampliando usos na aldeia e fora dela, para que os falantes vejam razão em ler e escrever na língua materna; do contrário cairão na falta de motivação para lutar pela sua inserção social, por perceberem que suas línguas não circulam em espaços legitimados.

Cavalcanti e Maher $(2005$, p. 7$)$ nos dizem que bilinguismo, "com certeza, não é saber duas línguas perfeitamente. É transitar de maneira confortável entre duas línguas. Ou, como defende Maher (2007), é 'a capacidade de fazer uso de mais de uma língua'". As autoras nos lembram ainda que o bilinguismo só é aceito na sociedade quando se incluem línguas de prestígio internacional (inglês, francês, alemão, italiano etc.), não entrando nessa geopolítica as línguas indígenas, evidenciando que essas línguas, assim como seus falantes, não têm validade, padecem na inexistência, apagamento, silenciamento e em outras sentenças tão comuns às minorias: "em uma sociedade que cobra um bilinguismo de línguas hegemônicas, uma pessoa pode até falar outra língua, mas tem receio de se considerar bilíngue se a língua que fala não é de prestígio" (CAVALCANTI, MAHER, 2005, p. 7).

Nos casos em que a Educação Escolar Indígena é uma realidade, como em algumas aldeias da região, os profissionais envolvidos no processo educativo devem perseguir formas de ensino que não contradigam o princípio bilíngue do ensino de línguas para indígenas, seja no currículo, nos assuntos abordados, nas metodologias e nos tempos de ensino na escola que não podem ser os mesmos que os de uma

3. Assim como é consenso entre os estudiosos que refletem sobre o ensino bilíngue em contextos bilíngues de que é salutar desenvolver o ensino de línguas tendo o bilinguismo aditivo como referência. 
escola de tradição urbana. Para subsidiar esse trabalho que objetiva uma educação diferenciada, contamos com:

$\sqrt{ }$ A Constituição de 1988, artigo 231 - assegura aos povos indígenas o direito de terem uma cultura e uma língua própria;

$\sqrt{ }$ A lei 9.394/96, artigo 210, parágrafo 3 - diz que "O ensino fundamental regular será ministrado em língua portuguesa, assegurada às comunidades indígenas a utilização de suas línguas maternas e processos próprios de aprendizagem";

$\sqrt{ }$ A lei 6.001/73, artigo 48 - estende à população indígena, com as necessárias adaptações, o sistema de ensino em vigor no País; artigo 49 - assegura que a alfabetização dos índios far-se-á na língua do grupo a que pertencem, e em português, salvaguardado o uso da primeira.

Já nos casos das escolas urbanas, em que um ensino diferenciado encontra barreiras muito maiores, o reconhecimento dos alunos indígenas como falantes, ao menos, bilíngues é o que permite dar passos firmes rumo a uma educação que respeite essa condição dos indígenas nas escolas da cidade, de forma a não mais ignorarmos que nossas salas de aula urbanas no sul \sudeste paraense são compostas pela diferença. Com isso, torna-se incoerente a imposição do monolinguismo em português que se tem feito historicamente no ensino de língua portuguesa, que só dificulta a aprendizagem dos alunos e solidifica preconceitos.

Após essa inserção em noções acerca do bilinguismo, destacamos que o fato de constituída por diversos povos indígenas, com línguas próprias, configura a mesorregião sudeste do Pará como um espaço plurilíngue, onde os sujeitos estão imersos em uma política monolíngue que não só deixa de reconhecer a riqueza linguística dos vários povos da região, mas também apaga e contribui, assim, para a morte dessas línguas e para o enfraquecimento das culturas dessas sociedades indígenas. Essa percepção plurilíngue sobre a região poderia ser uma forma de reestruturar as bases da formação dos professores da educação básica nos municípios do sul \sudeste do Pará, entendo-os como meios não-homogêneos, mas naturalmente compostos pela diferença, por alunos que pertencem a tradições culturais diversas, incluindo a tradição oral das sociedades indígenas. Diante disso, invisibilizar esses alunos na sua condição sociocultural é uma violência, é imergilos em uma lógica homogeneizante que beneficia apenas uns poucos alunos das escolas públicas que mais se familiarizam com os bens culturais (como língua e outros sócios-conhecimentos) que circulam na classe social hegemônica.

Nesse contexto de contato com o branco, embasamo-nos em Hamel (1988) para destacar a importância da valorização da língua dos alunos indígenas não apenas 
para o êxito escolar, mas também para o fortalecimento da cultura e língua dos povos a que pertencem. Isso evidencia mútuo benefício como fruto de uma relação imbricada entre essas categorias, de forma que essa relação não pode ser dispensada no trabalho de planejamento educacional em regiões com presença indígena em escolas que não possuem uma especificidade indígena no currículo.

\begin{abstract}
Na maioria das experiências documentadas, tanto de minorias aborígenes como de imigrantes subalternos, percebe-se que o êxito escolar dos programas está ligado à sua capacidade de fortalecer e consolidar a língua materna em todas as suas dimensões e funções (comunicativa, cognitivo-acadêmica, afetiva, etc.). Estes programas têm contribuído a reduzir a discriminação no contexto escolar mediante a segregação temporal dos alunos minoritários ou a criação de uma consciência cultural de aceitação nos alunos da maioria, acompanhada de um fortalecimento da identidade cultural e linguística nos pequenos do grupo étnico minoritário [tradução nossa]. (HAMEL, 1988, p. 359)
\end{abstract}

A par da importância de reconhecer e valorizar a condição bilíngue de alunos indígenas, presentes também nas escolas da zona urbana, acreditamos que o bilinguismo aditivo (como fim a se alcançar no ensino de língua) ganha maiores condições de se concretizar se o processo de ensino-aprendizagem for embasado pela tríade Interculturalidade, Alternância e Letramento ${ }^{4}$. Entendendo que não podemos mais aguardar que os povos indígenas se integrem à sociedade "branca" de forma assimilacionista, devemos buscar que essa integração aconteça superando o ideal colonizador ocidental, de forma que as estruturas estatais se adequem às condições de existência dos povos da região, convertendo as lógicas verticais de divisão social em perspectivas horizontais que contemplem não apenas as diferentes culturas, mas uma ordem de fatores históricos, políticos, sociais, econômicos e epistemológicos.

\title{
2. TRÍADE PROPOSTA PARA FUNDAMENTR MODELOS DE ENSINO BILÍNGUE
}

Os fundamentos que defenderemos nos tópicos a seguir (Letramento, Interculturalidade e Alternância) foram reunidos no sentido de sugerir sustentação para modelos de ensino bilíngue, aproximando-se do propósito freiriano de educação, imbuído pelo compromisso de ultrapassar a função tecnicista de educação para, por meio da linguagem, trabalhar politicamente para que os povos indígenas tenham autonomia no ato de significar criticamente o mundo (produzindo ou interpretando

4. Obviamente que outros conceitos são possíveis para tal fundamentação, mas essa é a escolha que fizemos para nossa reflexão, diante do leque de categorias passíveis de serem candidatas para o mesmo trabalho. 
discursos), conforme os ensinamentos de Freire (2000) de que a leitura deve ser precedida pela leitura de mundo dos sujeitos.

É com esse intuito que propomos esses fundamentos para o ensino de língua, aproximando-nos ao que já defenderam Ribeiro e Bôas (2010) sobre a importância da área das linguagens na luta contra a hierarquização de leituras sobre o mundo, de forma que as minorias também tenham espaço para mostrar suas leituras por um processo de recriação dos sentidos, produzidos a partir do lugar de existência dos sujeitos e as implicações políticas e socioculturais desse espaço situado.

\subsection{Interculturalidade}

Defendemos que a Interculturalidade é um fundamento de extrema importância para a busca do bilinguismo aditivo no ensino para indígenas. Maher (2006, p. 27) já defendeu essa ideia, dizendo que

\footnotetext{
[c] omo a escola nos moldes ocidentais entra nas aldeias como decorrência do contato com o outro, com os não-índios, a questão da interculturalidade, isto é, do conseguir fazer dialogar comportamentos e conhecimentos construídos sob bases culturais distintas e frequentemente conflitantes é atualmente entendida como o esteio, a razão de ser da escola indígena.
}

Para além de pôr em diálogo duas culturas diferentes, fazemos a proposição da interculturalidade na perspectiva de Walsh (2010) por acreditar que o ensino bilíngue não deve ter fim em si mesmo, apenas para que os falantes consigam circular confortavelmente em duas línguas. Para além disso, o domínio desses códigos deve servir como ferramenta de emancipação social desses sujeitos, aproximando essa premissa ao que fala Soares (2008) sobre a "escola transformadora", cujo objetivo é fazer com que o aluno se aproprie do código/língua legitimada para circular em espaços hegemônicos de poder com o intuito de melhorar as condições de vida dos grupos minoritários aos quais pertence.

Nessa perspectiva, a Interculturalidade fundamenta o ensino bilíngue que tem o intuito que defendemos neste trabalho, o de mudar a estrutura que mantém a desigualdade, a inferiorização, os apagamentos e outros sentenciamentos desprivilegiados para os grupos minoritários. Para isso a Interculturalidade, nos termos de Walsh (2010), defende a equidade epistêmica no sentido de que as diferenças dos povos possam ser não apenas reconhecidas, mas ter o mesmo valor social, uma vez que "o reconhecimento e respeito se convertam em uma nova estratégia de dominação [tradução nossa]" (WALSH, 2010, p. 78). Assim é que a Interculturalidade nos inspira a requerer para o ensino bilíngue não apenas a valorização da língua menos prestigiada, mas que o ensino de língua carregue 
os conteúdos da cultura do povo em questão (Cf. SILVA, 2008), ou seja, seus etnoconhecimentos, e ainda seja transmitida em tempos e por meio de metodologias não estranhas às comunidades indígenas. Dessa forma, a Interculturalidade nos inspira a requerer para o ensino bilíngue um fim mais amplo, em que os sujeitos indígenas possam ser donos das suas próprias leituras e ganhem autonomia para escrever suas próprias histórias, que o ensino de língua se transforme em uma ferramenta para lutas políticas, para transformação social.

Diante disso, a concepção de interculturalidade entra em cena não para viabilizar o diálogo entre culturas diferentes, mas tornar visíveis (e praticáveis em nossa sociedade) outras formas de pensar e existir historicamente apagadas pelo conhecimento ocidental. É nesse sentido que a interculturalidade dá suporte às lutas contra-hegemônicas desses sujeitos (lembrando que a Interculturalidade, na América Latina, tem suas raízes nas discussões políticas colocadas pelos movimentos sociais, segundo Walsh, 2010, p. 89), defendendo a valorização dos "saberes e conhecimentos no intuito de mudar não só as relações, mas também as estruturas, condições e dispositivos de poder que mantêm a desigualdade, inferiorização, racialização e discriminação [tradução nossa]" (WALSH, 2010, p. 70). Além de reconhecer a diversidade nas várias formas de existir (seja no âmbito cultural, educacional, econômico e de trabalho) dos povos indígenas, o esforço deve ser para reconceituar e refundar as estruturas sociais, epistêmicas e de existência de forma a colocar em relação equitativa as diversas lógicas de pensar e existir. Essa percepção toma conotação ainda mais salutar no sul|sudeste paraense, ao ponderarmos essa região com um local de fronteira, onde estão em permanente batalha múltiplos projetos de territorialização, cenário esse propício a conflitos de várias ordens, sempre motivados pelo choque entre sistemas de produção distintos, embasados em paradigmas culturais e epistemológicos díspares.

Nesse sentido, percebe-se a importância de pensar modelos de ensino posicionados de forma ética e comprometida (teórico e metodologicamente) com o projeto de sociedade desses povos, ofertando um ensino de língua que vise transformações na concepção de escola, na metodologia de ensino e na organização do currículo. Nesses termos, a Interculturalidade se transforma em uma arma analítica e política não apenas para transformar os modos de fazer na educação, mas para reconceitualizar o mundo por meio dela. Como preconiza Freire (2000, p.114): "a democratização da escola não é puro epifenômeno, resultado mecânico de transformação da sociedade global, mas fator também de mudança".

Então, se o objetivo maior é a emancipação dos sujeitos minoritários, de forma que as epistemes distintas ocupem posições equitativas na sociedade, 
Walsh (2010) alerta que Estado, partidos políticos e teorias acadêmicas não são opções acertadas, já que neles não há espaço para colocar em xeque os interesses hegemônicos. E a Interculturalidade (assim como os fundamentos educacionais desses povos) coloca em questão os pressupostos epistemológicos que consolidam os projetos eurocentrados dessas instituições.

Assim, o projeto social e educacional dos povos minoritários exige uma opção decolonial (MIGNOLLO, 2008) do saber para uma educação indígena, no qual se reconheça "que o paradigma que estrutura a ciência moderna negligenciou a diversidade epistemológica do mundo e, assim, negou a sujeitos individuais e coletivos subalternizados a possibilidade de agenciamento epistêmico [tradução nossa]" (WALSH, 2010, p. 86). Na contramão disso, a área das linguagens, seja para ensino de língua ou literatura, deve trabalhar no sentido de garantir o direito a um ensino que contribua para a transformação de tal realidade segundo os interesses, desejos e necessidades de cada comunidade indígena, com suas peculiaridades sócio-históricas e identidades próprias. Assim, mais que "adequar" ao ensino para indígenas aquilo que foi pensado para uma escola formal homogênea (conteúdos, material didático e organização pedagógica da escola), o que se deseja afirmar é uma pedagogia e escola que contemplem as especificidades dos sujeitos indígenas, contextualizadas e vinculadas à existência e a projetos dos diversos sujeitos que compõem a sala de aula urbanas (ou as diversas comunidades, no caso da Educação Escolar Indígena).

É nesse sentido que a área das linguagens se insere nessa concepção de educação, absorvendo um novo posicionamento epistêmico para interpretar e produzir discursos nas relações sociais, entendendo que a linguagem (nas suas várias abordagens) perpassa todos os campos da atividade humana, de forma que nascemos e vivemos no universo simbólico da linguagem, por meio do qual se aprendem, se materializam e se perpetuam os conhecimentos de uma cultura. Assim, reforçamos a premissa de que o ensino não é producente para nenhum aluno $^{5}$ quando centrado no puro domínio técnico da língua legitimada, pois, como destaca Soares (2008), assim só se garante que a ordem hegemônica seja mantida, ordem essa pautada na naturalização da superioridade e neutralidade da hegemonia e sua língua, o português mais próximo do padrão.

5. E isso se complica ainda mais quando se trata de um aluno indígena que faz uso de outra língua ou outra variante do português que não é a mesma da usada pelos não-índios. 


\subsection{Letramento}

Segundo Kleiman (2008, p. 268), o Letramento se dá "quando o ensino de língua vai além da mera análise da língua e passa a ser pensado como uma prática, portanto da ordem da ação social [gêneros / práticas discursivas X contextos discursivos]". É desse ponto que queremos partir, apontando os estudos do Letramento como uma saída para o êxito do ensino bilíngue, uma vez que, em se tratando de grupos minoritários como os indígenas, "a perda da identidade desses grupos está geralmente simbolizada pela perda da língua (ou variação) materna, em consequência de um processo de deslocamento linguístico na direção da língua dominante" (KLEIMAN, 2008, p. 268).

Assim, acreditamos que ensinar a ler e escrever a partir das práticas sociais que o aluno de fato vivencie no cotidiano é uma forma de contemplar a língua do aluno, os usos que faz dela em comunidade, os conhecimentos que mobiliza na interação, colaborando assim para a afirmação da identidade linguístico-cultural. É a partir da proposta freiriana de leitura política do mundo que os estudos do letramento têm subsidiado modelos de ensino voltados para as práticas cotidianas da linguagem, impulsionando um letramento ideológico (STREET, 1984) que parte do mundo dos sujeitos, da sua cultura, e as ações de leitura e escrita nesse contexto. Ou seja, para o autor, o letramento ideológico é definido pela vinculação da escrita aos contextos sociais que a mesma circula, de forma que os sentidos do texto não são dicionarizados, mas arraigados aos sujeitos e os meios (contextos \instituições) em que a escrita é colocada em prática.

É nesse sentido do letramento que direcionamos nossa reflexão para o ensino bilíngue na educação para indígenas, acreditando que a ação deve estruturar o ensino de línguas; ações essas que são inerentes às práticas discursivas do aluno em comunidade e não produções socioculturalmente descontextualizadas, seja pelo gênero e/ou pelo conteúdo de que trata. E quando pensamos nos gêneros para o ensino de língua, Kleiman (2008, p. 509) adverte que é a prática linguística que deve mobilizar o gênero e não o contrário - quando o letramento orienta o ensino "não corre o risco de algum conteúdo do currículo deixar de ser contemplado, pois a habilidade de articular o gênero ao contexto de uso da língua e adequar a linguagem a esses é o objetivo final de qualquer projeto de ensino de línguas".

Com isso a autora defende que o modelo de ensino de língua tendo como referência o Letramento, em seus fundamentos teóricos, tem dado bons resultados em projetos de formação de professor no contexto de ensino de línguas em que atua o professor em formação, considerando para isso as especificidades do aluno, os objetivos sociopolíticos da comunidade, o modelo de escola e seu currículo. Dessa 
forma, os estudos do Letramento podem ser efetivados por meio de: metodologias que estimulem a autonomia dos alunos; currículos que estejam em consonância com os objetivos políticos e socioculturais dos povos a que pertencem os alunos; e com conhecimentos produzidos pelos povos indígenas, já que "uma política linguística que pretende valorizar a língua indígena não pode ser dissociada da valorização dos conteúdos contidos nessa língua, ou seja, da valorização da cultura do grupo" (SILVA, 2011, p. 64).

Assim, o conceito de "letramento ideológico" permite que sejam inseridos no ensino de língua para indígenas princípios e ações caros às culturas dos povos, como participação nos tempos (religiosos, cultivos, colheitas etc.) da aldeia, lembrando que esses momentos são realizados na modalidade oral da língua, de forma que a oralidade precisa ser considerada nas atividades do letramento. Mesmo após a descrição de algumas línguas para facilitar o processo de letramento na língua materna indígena, não podemos esquecer que os povos indígenas são tradicionalmente ágrafos e que a escrita não pode, nem deve, dar conta de processos de interação pautados na oralidade. Por isso, portanto, o letramento não deve sufocar os usos orais dos falantes de uma língua indígena, uma vez que os momentos de sociabilidade oral são muito mais presentes nessas comunidades do que na lógica ocidental de culturas massivamente grafocêntricas.

\subsection{Alternância}

Para reforço ao êxito do bilinguismo aditivo, além da Interculturalidade e do Letramento como fundamentos, o terceiro elemento que sugerimos para ser considerado no ensino em contextos que envolvam indígenas é a Alternância. Maher (2008, p. 28) já reconheceu essa necessidade ao pensar em inovações para a escola indígena.

sem considerar que os princípios da pedagogia indígena estão assentados em outra noção de tempo de ensino e tempo de aprendizagem (...) Ora, o novo modelo de escola indígena pressupõe, entre outras coisas, a construção de um calendário escolar culturalmente específico: em época de colheita e dos rituais a ela associados, por exemplo, as atividades têm que ser interrompidas na escola de modo a permitir que os alunos possam acompanhar os adultos nessa importante esfera de socialização. É preciso insistir no fato de que a escola indígena que se quer é aquela que seja capaz de preparar os alunos indígenas para os desafios que o contato com a sociedade envolvente impõe sem, no entanto, desrespeitar suas crenças e práticas culturais.

Com isso destacamos que já é ponto pacífico acreditar que os tempos de vivência em comunidades são imprescindíveis para o aprendizado quando se trata de grupos não regidos pela lógica urbana de produção e trabalho, de forma que o 
aprendizado exige a alternância entre os espaços formais de ensino, a escola, e a vivência nos tempos (religiosos, culturais, de plantio, colheita etc.) da comunidade. Dessa forma, o aluno poderá refletir os aprendizados adquiridos na escola em sua realidade socioeconômica, política, ambiental e cultural, além de ter esse mesmo espaço social, o lugar onde vive, como fonte de pesquisa, contextualizando os materiais produzidos no processo de aprendizagem (ARROYO, 2007).

Assim, a alternância pode ser uma na qual o ensino caminhe de forma dialógica por dois espaços, a escola formal e a comunidade, fazendo com que os conhecimentos do seu povo, construídos ao longo da história, não sejam desconsiderados na escola, acostumada a ter a ciência ocidental como referência única para as práticas de ensino. Nesse sentido, Levi-Strauss (1976) nos habilita a considerar a validade desses conhecimentos (que chama de "ciência do concreto") dos povos originários na sala de aula, tanto para contribuir na aprendizagem dos alunos indígenas quanto para o fortalecimento desses conhecimentos como válidos na sociedade tanto quanto os ocidentais.

O autor argumenta que a ciência do concreto, a ciência dos povos tradicionais, não difere da ciência moderna no sentido de que esse saber não legitimado também é alcançado pela exaustão de experiências para fornecer resultados práticos e utilizáveis. Exemplo disso são as várias técnicas avançadas na metalurgia, engenharia, botânica, climatologia, entre outras, utilizadas milenarmente por essas sociedades. Enquanto o conhecimento moderno classifica esses conhecimentos como "ritos" e "mitos", o autor os posiciona na ponta de uma régua que traz a ciência moderna na outra extremidade. Para ele, trata-se de dois modos de abordar cientificamente o mundo, a natureza: um mais ligado à percepção, à imaginação, ao sensível, tendo o homem integrando a natureza; e o outro que tem o homem deslocado da natureza, regido pela lógica da dominação.

os mitos e os ritos oferecem como valor principal a ser preservado até hoje, de forma residual, modos de observação e de reflexão que foram (e sem dúvida permanecem) exatamente adaptados a descobertas de tipo determinado: as que a natureza autorizava, a partir da organização e da exploração especulativa do mundo sensível em termos de sensível. Essa ciência do concreto devia ser, por essência, limitada a outros resultados além dos prometidos às ciências exatas e naturais, mas ela não foi menos científica, e seus resultados não foram menos reais. Assegurados dez mil anos antes dos outros, são sempre o substrato de nossa civilização. (LEVI-STRAUSS, 1976, p. 31)

Nesses moldes, os saberes dos povos indígenas também podem tomar status científico, entrar no espaço escolar e vestir a autoridade da "ciência", tornando a aldeia também um espaço de aprendizado e de produção do conhecimento para a escola urbana, desmitificando a ideia de que o conhecimento só pode ser produzido 
com ferramentas disponibilizadas pelo espaço formal de ensino. Nesse sentido, Gregolin $(2015$, p. 11) observa que Foucault nos ajuda a avaliar como as relações de poder na sociedade legitimam determinados saberes e outros não:

Por ter-se ocupado das relações entre discursos, saberes e poderes, Foucault revolucionou as teorias clássicas do Estado, na medida em que introduziu, nas análises históricas, a ideia de que o poder pode ser considerado como instrumento analítico capaz de explicar a produção dos saberes.

Chegando a esse ponto da reflexão, esse exercício nos faz concluir que a Alternância, como viabilidade de fazer o conhecimento formal ser condicionando à realidade de vivências dos alunos, é o que permite que o Letramento seja praticável e que a Interculturalidade se efetive no objetivo de equidade epistêmica, além de garantir que o aluno não deixará de participar das vivências em comunidade para estar na sala de aula. Dessa forma, percebemos o entrelaçamento viável e coerente da tríade que propusemos neste trabalho para o ensino de língua em escolas com alunos indígenas.

\section{LINGUÍSTICA APLICADA E O COMPROMETIMENTO ÉTICO COM O ENSINO DE LÍNGUA}

Os fundamentos aqui propostos à estruturação de modelos de ensino bilíngue para indígenas requerem que o trabalho do professor, e de pesquisadores que enveredam nessa tarefa, tenha comprometimento ético e político com os sujeitos indígenas. Não é à toa que se tem defendido insistentemente que os professores para alunos indígenas também devem ser da mesma etnia e não um professor branco, já que ninguém melhor que um professor indígena para pensar conteúdos e metodologias que melhor atendam à cultura do seu próprio povo. Mas como ainda é reduzido o número de pesquisadores indígenas com formação que lhes forneça legitimidade acadêmica para fazer proposições teórico-metodológicas que atendam às necessidades de seus povos, pesquisadores não-indígenas é que têm se dedicado a essa missão, porém Oliveira (1999) nos adverte quanto ao fato de que muitos linguistas que fazem assessoria para comunidades indígenas estão mais comprometidos com suas bases teóricas do que com as necessidades dos grupos.

Nesse mesmo sentido, Rajagopalan (2006, p. 158) também chama a atenção para a importância de os estudos linguísticos estarem a serviço dos interesses da sociedade e não em uma "torre de marfim" que serve apenas para comunicações entre pares e em nada atingem as necessidades da sociedade: "É desnecessário 
apontar que uma linguística concebida dentro de uma torre de marfim, isto é, sem se preocupar com o que ocorre no mundo real, tem pouca relevância ou utilidade no dia a dia para a vida das pessoas comuns".

Com isso, o autor destaca a importância de avaliarmos se as pesquisas não estão situadas em "[u]ma teoria concebida à revelia das preocupações práticas, elaborada apenas para satisfazer a criatividade de um gênio solitário, [que] não tem valia alguma no campo da prática" (RAJAGOPALAN, 2006, p. 159). É nesse ponto que diferencia os pesquisadores aplicados dos teóricos. Enquanto os primeiros assumem em suas pesquisas um comprometimento político contra-hegemônico, os segundos estão engessados a concepções científicas positivistas que embasaram a fundação da Linguística enquanto disciplina.

Enquanto estiverem comprometidos com um dos princípios fundadores da disciplina, os linguistas teóricos não têm como intervir ativamente em questões como planejamento linguístico - e por tabela, na vasta gama de assuntos que interessam ao linguista aplicado. (RAJAGOPALAN, 2006, p. 155)

Por isso, ressalto que o caminho seguido nessa reflexão foi inspirado em leituras acerca da Linguística Aplicada (LA), campo em que as discussões e reflexões em torno do ensino bilíngue têm abrigo, tentando mostrar como os princípios da área sustentam nossa proposta de fundamentar o ensino para indígenas na prática social (Letramento) para propor resultados concretos não apenas no ensino de língua, mas em problematizações epistêmicas numa contextualização social mais ampla (Interculturalidade), considerando as temporalidades dos sujeitos contemplados no processo de ensino-aprendizagem (Alternância).

Para tanto, esse entrecruzamento só é possível se ponderarmos que a LA nos permite desenvolver um processo de construção do conhecimento com outras áreas para além da Linguística, num movimento interdisciplinar, já que a LA é essencialmente interdisciplinar. Assim, consideramos que o diálogo do ensino bilíngue com Interculturalidade, Letramento e Alternância é um movimento coerente e aceitável no pensamento mestiço da LA (MOITA LOPES, 2006), opondo-se às perspectivas de pesquisas que se limitam a pensar a língua regidas por princípios positivistas, princípios estes estruturantes na fundação da Linguística como ciência na qual sobressai a neutralidade, a pesquisa isenta de valores:

uma das características da LA contemporânea é o envolvimento em uma reflexão contínua sobre si mesma: um campo que se repensa insistentemente (Cf. Pennycook, 2001: 171). Tal característica pode ser bastante problemática para campos cristalizados, seguidores de visões de conhecimento como construção de verdade. 
Essa dificuldade é principalmente maior para aqueles que atuam no campo dos estudos linguísticos sem familiaridade com muito da discussão das humanidades e nas ciências sociais, onde a pesquisa em LA está situada (Cf. Cavalcanti, neste volume). Em outras palavras, isso é especialmente um problema para aqueles que trabalham com definições muito claras (fundamentalistas ou essencialistas, talvez?) do que o campo de estudos da linguagem é e faz..."

(...) É assim que Phillipson \& Skutnabb-Kangas (1986) criticam uma Linguística que, mais do que passar ao largo das questões sociopolíticas, colabora na manutenção das injustiças sociais ao não situar seu trabalho nas contingências e vicissitudes sócio-históricas e ao não se indagar sobre os interesses a que seu trabalho serve (MOITA LOPES, 2006, p. 17 e 21).

Ainda nessa perspectiva, Moita Lopes (2006) destaca que na Linguística Aplicada o pesquisador é essencialmente interpelado pelo sentido de se posicionar eticamente em favor da comunidade com a qual trabalha, problematizando a quem a produção do conhecimento beneficia. Nesta reflexão, situar nossos fundamentos (Letramento, Interculturalidade e Alternância) na LA é importante para não perdemos de vista a concepção de linguagem como lugar de disputa para legitimar verdades sobre o mundo e que os indígenas se encontram em desvantagem nessa luta por não terem suas línguas reconhecidas e valorizadas nos espaços hegemônicos da sociedade, de forma que o ensino bilíngue deve dar condições para que esses sujeitos tenham suas leituras de mundo e que essas tenham a mesma circulação de outras de maior prestígio, podendo assim fazer circular suas vivências, que são apagadas da história.

Dessa forma, não poderia encerrar sem situar essa discussão no campo da LA, entendendo que nossas proposições têm o intuito de se somar às reflexões que vêm sendo feitas em torno do ensino bilíngue, como forma de efetivar mudanças na sociedade tendo a linguagem como meio para tal empreitada. E no caso da linguística isso pode ser feito por meio de reflexões sobre o ensino de língua (como estamos fazendo aqui), mas um ensino que priorize a busca por legitimar no máximo de espaços sociais a língua dos povos minoritários, por meio de um modelo de ensino que atenda os anseios dos sujeitos subalternos, neste caso, os indígenas, no sentido de valorizar a cultura dessas sociedades para que o ensino de língua possa dar condições para circular suas próprias histórias, contadas por elas mesmas.

Com isso, precisamos atentar para o fato de que o professor que atua(rá) na educação básica deve ao menos ser lembrado de que a região sul \sudeste paraense é plurilíngue e que o profissional de letras terá em sua sala um aluno que não tem o português como língua materna, Nesse sentido, Cavalcanti e Maher (2005, p. 20) nos advertem de que nossas graduações: 
...continuam formando pessoas para trabalhar com o falante nativo ideal em uma comunidade de fala homogênea, sem conflitos ou problemas de qualquer espécie. A escola parece conseguir ficar distante do contexto socio-histórico e "sobreviver". E isso é suficiente para os tempos atuais de tantas e tão rápidas mudanças? Como já apontei (Cavalcanti, 1999a, entre outros), não vejo a culpa com os professores. Os cursos de formação de professores dentro da conjuntura atual de políticas linguísticas (muitas vezes não explícitas) e de políticas educacionais devem arcar com essa culpa sobre o status quo. A diversidade linguística e cultural precisa ser parte da sala da aula, das comunidades envolventes, dos cursos de formação.

Essa crítica das autoras nos dá uma amostra de como os estudos linguísticos precisam se aproximar dos problemas encontrados em sala de aula, o que a LA tem feito (não apenas na sala de aula) no sentido de se construir como uma teoria que busca estar a serviço das necessidades da sociedade. O caráter mestiço da LA (em diálogo com outras áreas do conhecimento, em especial com as Ciências Sociais) tem permitido pontuar a necessidade interdisciplinar no modo de fazer pesquisa nos estudos linguísticos e no impacto dessas proposições para o ensino de língua, uma vez que tem dado subsídios teóricos e epistemológicos para que as pesquisas sobre a língua tenham cada vez mais proximidade com as necessidades dos grupos minoritários da sociedade.

Em consequência disso, tem-se repensado o ensino de língua em determinados contextos com base nesses construtos teóricos da LA, de forma que as proposições nessa área acabam se efetivando com comprometimento ético com os grupos sobre os quais se reflete, buscando, de fato, propor alternativas que podem ser efetivadas no contexto de pesquisa, refletindo em benefícios para esses grupos com quem se trabalha.

\subsection{Educação como dispositivo: ensino do português para mudança social}

Ao propor o conceito de dispositivo, Foucault inaugura a reflexão de que o poder se manifesta e busca se manter enquanto tal por meio de instrumentos institucionalizados na sociedade e a Educação seria um deles. Nesse sentido, o poder negocia as tensões com os sujeitos do momento histórico em questão, de forma a se mobilizar de acordo com as condições sócio-históricas a fim de perpetuar seus espaços de automanutenção, mesmo que as formas como esse poder se instaura sejam modificadas ao longo da história por condicionamentos dessa negociação considerar a Educação como um dispositivo.

Sabe-se que a educação, embora seja, de direito, o instrumento graças ao qual todo o indivíduo, numa sociedade como a nossa, pode ter acesso a qualquer tipo de discurso, segue, em sua distribuição, no que permite e no que impede, as linhas que estão marcadas pela distância, 
pelas oposições e pelas lutas sociais. Todo sistema de educação é uma maneira política de manter ou de modificar a apropriação dos discursos, com os saberes e os poderes que eles trazem consigo. (FOUCAULT, 2011, p. 44)

Essas linhas de que o autor fala não delimitam ou envolvem sistemas homogêneos, mas compõem processos em permanente desequilíbrio, que são chamados por ele de "dispositivos". No caso da nossa reflexão podemos entender a escola como um dispositivo, nos moldes do que trabalhou Gregolin (2015). Esse desequilíbrio do dispositivo escolar é mantido pela atuação dos sujeitos, pela produção de subjetividades geradas como respostas às manifestações de força do dispositivo, que atua para manter sua ordem hegemônica. Em outras palavras, o desequilíbrio é um reflexo das negociações entre o poder e o sujeito subjetivado pelo dispositivo. Assim, as produções de subjetividade dos sujeitos podem tensionar a tal ponto o dispositivo que chegam então a provocar sedimentações, ou reconfigurações, ou mudanças ou até mesmo transformações radicais no dispositivo, a ponto de possibilitar a emergência de um novo modo de ser do dispositivo (DELEUZE, 1996).

Esse conceito foucaultiano de dispositivo nos permite visualizar como o sistema escolar (um dispositivo) precisa ser tensionado para que sua ordem possa ser descontinuada, fazendo com que (dependendo da forma e intensidade como as produções de subjetividade dos sujeitos se manifestam) se sedimente ou assimile pequenas alterações, ou mesmo se frature.

É a partir dessa perspectiva que defendemos que o ensino do português nas escolas pode ter condições de considerar a língua nas várias facetas que compõem sua unidade (como ato político, ideológico, cultural, logo, social) para funcionar como instrumento de mudança social e não apenas de transmissão de técnicas de leitura e escrita. Assim, entendemos que o ensino de língua, pautado nesse tripé: Letramento, Alternância e Interculturalidade, pode ser uma forma de desestabilizar o dispositivo escolar a favor de mudanças favoráveis aos grupos minoritários, com os indígenas de que tratamos neste trabalho.

\section{CONSIDERAÇÕES FINAIS}

Nosso apontamento à tríade Letramento, Interculturalidade e Alternância como fundamentais para se pensar modelos de ensino bilíngue aos indígenas se deu a partir de leituras dos trabalhos de diversos pesquisadores que têm problematizado o ensino bilíngue para esses sujeitos, especialmente pesquisadores situados na LA. Nessas leituras, tínhamos o desejo de buscar o que poderia estruturar modelos 
de ensino nessa conjuntura e chegamos à conclusão de que esses fundamentos contemplam algumas das necessidades dos povos indígenas em contexto de ensino de língua, o que só pode ser confirmado pelos próprios indígenas.

Assim, esse tripé é o que propomos como fundamentos primordiais para subsidiar modelos de ensino que: 1) partam das práticas sociais dos alunos; 2) respeitem os tempos que a cultura da comunidade exige e considere as vivências do aluno em comunidade como momentos de aprendizagem, de ele refletir sobre o que aprendeu na escola e aplicar; 3 ) evidenciem o ensino para além de sua função educativa formal, mas para a emancipação dos povos indígenas de forma que esses sujeitos possam estar cada vez mais instrumentalizados nas lutas para ter sua cultura, modos de pensar e existir considerados tão válidos quanto as práticas regidas pelas epistemes ocidentais.

Tentamos demonstrar que há viabilidade de diálogo entre os três fundamentos e que poderíamos situá-los em um campo maior para nortear as reflexões em torno do ensino bilíngue, que é o campo da Linguística Aplicada, justificando assim a união que forma esse tripé, que seria o objetivo de colocar o ensino de língua a serviço da emancipação dos povos indígenas, pois ter como alvo apenas reconhecer a língua dos indígenas dá lugar a poucas mudanças sobre a vida prática desses sujeitos, lembrando o que nos diz Walsh (como já citamos) sobre o perigo de o reconhecimento e o respeito à diversidade cultural se transformarem em uma nova estratégia de dominação.

A partir dessa mesma autora é que consideramos que, em consenso com a Linguística Aplicada, o ensino bilíngue para indígenas deve ser pautado por um projeto maior, o da emancipação desses sujeitos, para conquistas sociais maiores em uma sociedade movida pelo conhecimento moderno como a nossa, que silencia, e mesmo oprime, outras formas de pensar e existir que não se enquadrem na lógica ocidental.

Esse ensino bilíngue deve servir então para que essas sociedades possam circular nos espaços legitimados e transformar as estruturas de dominação e poder. Esse ensino bilíngue deve servir para que os sujeitos originários não dependam do Outro para escrever sua história (está mais do que provado que isso não dá certo, pois a visão das minorias sempre é apagada e silenciada) e para que possam lutar por equidade epistêmica (e essa epistemologia possa circular por espaços hegemônicos, como nos livros usados pelos alunos nas escolas), desestruturando a escola como espaço de reprodução das desigualdades do contexto social regional (considerando a Educação como um dispositivo, nos termos de Foucault) para seguir uma nova forma de trabalho, que viabilize a possibilidade da história desses grupos minoritários 
serem contadas por eles próprios, a partir das suas interpretações de mundo nas vivências de conflito com a hegemonia ao longo da história.

\section{REFERÊNCIAS BIBLIOGRÁFICAS}

ARROYO, M. G (2007). Políticas de formação de educadores(as) do campo. Cadernos CEDES. Vol. 27, N. 72, p. 157-176.

CAVALCANTI, M. do C.; MAHER, T. J. M. O índio, a leitura e a escrita: o que está em jogo? São Paulo: Rever - Produção Editorial, 2005.

DELEUZE, Gilles. O que é um dispositivo? In: O mistério de Ariana. Lisboa: Vega/Passagens, 1996.

FOUCAULT, Michel (1970). A ordem do discurso. Aula Inaugural no Collège de France. Pronunciada em 2 de Dezembro de 1970. 21 a ed. São Paulo: Loyola, 2011.

FREIRE, P. Pedagogia da esperança: um reencontro com a Pedagogia do oprimido. 7. ed. São Paulo: Paz e Terra, 2000.

GREGOLIN, Maria do Rosário (2015). O dispositivo escolar republicano na paisagem das cidades brasileiras: enunciados, visibilidades, subjetividades. Revista Moara- Estudos Linguísticos. Belém, Edição 43, p. 6-25.

HAMEL, R. E (1988). Determinantes sociolingüísticos de la educacción bilíngue. SIGNOS: Anuário de Humanidades. UAM-I, p. 319-375.

KLEIMAN, A. B (2008). Os estudos de letramento e a formação do professor de língua materna. Linguagem em (Dis)curso. V. 8, N. 3, p. 487-517.

MAHER, T. J. M. (1996). Ser professor sendo índio - questões de língua(gem) e identidade. Tese de Doutorado em Linguística. Instituto de Estudos da Linguagem, nicamp, Campinas.

MAHER, T. J. M. (1998). Sendo índio em português. Língua. V. 18, p. 115-138.

MAHER, T. J. M. A formação de professores indígenas: uma discussão introdutória. In: GRUPIONI, Luís Donisete Benzi (Org.). Formação de professores indígenas: repensando trajetórias. Brasília: Ministério da Educação, Secretaria de Educação Continuada, Alfabetização e Diversidade, 2006. 
LÉVI-STRAUSS, Claude (1962). O Pensamento Selvagem. São Paulo: Companhia Editora Nacional, 1976

MIGNOLO, W (2008). Desobediência epistêmica: A opção decolonial e o significado de identidade em política. Cadernos de Letras da UFF, N. 34, p. 287-324.

MOITA LOPES, L. P (2006). Uma linguística aplicada mestiça e ideológica: interrogando o campo como linguista aplicado In: , Por uma linguística aplicada INdisciplinar. São Paulo: Parábola Editorial, 2006.

OLIVEIRA, G. M (1999). O que quer a Linguística e o que se quer da Linguística. Cadernos Cedes, V. 49, p. 26-38.

RAJAGOPALAN, Kanavillil. Repensar o papel da Linguística Aplicada In: MOITA LOPES, L. P. Por uma linguística aplicada INdisciplinar. São Paulo: Parábola Editorial, 2006.

RIBEIRO, N. B.; VILLAS BÔAS, R. L. O processo em construção da Área de Linguagens na Educação do Campo In: Memória e bistória do Pronera: contribuições para a educação do campo no Brasil. Brasília: Ministério do Desenvolvimento Agrário, 2010.

SILVA, S. S. (Org.). Línguas em contato: cenários de biliguismo no Brasil. Campinas, SP: Pontes Editores. 2011.

STREET, B. V. Literacy in theory and practice. Cambrigde: Cambrigde University Press, 1984.

WALSH, C. Interculturalidad crítica y educación intercultural. III CAB. La Paz: Convênio Andrés Bello, 2010

Recebido: $11 / 05 / 2017$

Aceito: 08/08/2017 